\title{
ROBOT DESIGN USING PROJECT ORIENTED AND COLLABORATIVE LEARNING TOOLS
}

\author{
Carlos Pfeiffer*, Josep M. Mirats Tur**, Jesus Santana* \\ *Instituto Tecnológico de Estudios Superiores de Monterrey \\ Monterrey, N.L., Mexico. \\ **Institut de Robótica i Informática Industrial \\ Barcelona, Spain.
}

jmirats@iri.upc.edu, pfeiffer@itesm.mx, santana@itesm.mx

\begin{abstract}
In the last years applied robotics is being incorporated to the undergraduate curriculum of electrical and mechanical engineering and computer science. Design courses on robotics usually utilize a standard commercial platform, like legos or other educational kits, and the students are given a common task to solve using the kit. However, one of the most important challenges professional engineers must deal with is not only to propose a novel solution for a given problem, but also to identify opportunity areas where they can use their knowledge to develop a new product. Most robotics courses curriculum do not emphasize this process. In this paper we describe a robots design course based on the didactic technique POL (Project Oriented Learning) where the students identify an opportunity area for a robot project application, propose a design, and build a working prototype. The work is done on teams using collaborative learning. Robot design classes under this schema facilitate the students integration of their knowledge in several areas, giving as a product original and creative robotic applications.
\end{abstract}

\section{INTRODUCTION}

Faster and faster new technological advances are being incorporated to our daily life. This is the case of robotics, which can assist or even substitute us on doing tedious, monotonous, or in some cases even dangerous activities as domestic cleaning, fire fighting, automatic surveillance, etc. Robotics has also begun to appear on leisure applications like games and toys.

Robotics itself can also be used for education purposes. Nowadays, it is of the maximum relevance that computer, electrics, control or mechanical engineering university program studies include the teaching of both theoretical and practice courses on robotics. While traditional technical education strategies trend to promote individualism and competence between students, nowadays engineering challenges in most areas, and specially robotics, requires working with multidisciplinary teams in order to successfully integrate different areas of knowledge. Practical work on robotics at university level can help engineering students to develop the needed communication and working skills for teamwork.

In this paper we describe the course on "Robots Design" that electronics systems engineers take in their last semester at the Instituto Tecnológico de Estudios Superiores de Monterrey, Campus Monterrey, Mexico. We propose the use of Project Oriented Learning (POL) [2], and Collaborative Learning [3] for a course on robots design.

\section{METHODOLOGY}

The course on robot design that students take at the ITESM, has as main objective to get the students as close as possible to solve a real problem and give the students the possibility of integrating knowledge of subjects taken on previous semesters: microprocessors, sensors and actuators, wireless communications, Internet distributed applications, programming, real time systems, robot kinematics and dynamic modeling, computer vision, artificial intelligence, digital and analog electronics, circuit design, instrumentation and control theory. 
During the course they will work in groups of 3 or 4 people in order to get a functioning prototype at the end of the term. Although most students belong to the electronic systems major, students from other majors as mechanical, mechatronics, electronics and communication engineering are also encouraged to take the course, forming multidisciplinary teams.

Typical robotics courses on most universities provide the students a common robotic kit to be assembled to solve an specific task [4,5]. One differentiate characteristic of the course at ITESM is that students are encouraged to propose their own ideas on the basis of useful projects whether for industry, home or entertainment applications. That is, they are motivated to think about proposing solutions to real problems and their social implications, to develop the project requirements, to evaluate the design parameters of the project and to implement an adequate work planning.

At the first class the students are asked to bring 3 or 4 project proposals, together with a brief preliminary analysis of the work they imply. On the second class, one week later, each team explain and discusses their proposals with the professor and the rest of the groups. This process enriches the learning of all the students in the class; being exposed to the ideas of the others creates an excellent environment to develop and practice communication and criticism skills. Usually the students trend to propose robotics projects that are too ambitious for a semester term (with 4 month of real available time to work), and the role of the professor is very important in the first stage to help the students to limit the projects so its feasible to build a working prototype on this period of time. Hence, the main role of the professor here is to advise the teams in the technological feasibility analysis of their projects, and after this stage, according to the POL philosophy the students are encouraged to take responsibility of their own learning, being the professor only an adviser and moderator of the class.

In order to build their projects prototypes, the students are free to decide whether they will build their own structures, use parts of toy vehicles or recycled electronics and mechanical parts from disclaimed hardware as old computers, printers, plotters, etc., or use commercial robot kits. The institution provides them with components as step motors, sensors, transmissions, power sources, microcontrollers, signal analyzers and labs working spaces.

After project selection stage, each team meets weekly with the professor for advice and to check the status of the project. This interaction is essential for a timely development of the projects.

Every four weeks each team gives a seminar on the advances of their project to all the students in the class. The presentations include the mechanical design of the robot, the involved electronics, and the developed software/strategy. The last seminar is a demonstration of the full working prototypes.

\section{PROJECT DOCUMENTATION}

During the semester each team continuously report their work on a web page, including schematics, programming code, flow diagrams, given presentations, photographs, videos and other relevant information about their advances. This technique of documentation has prove to be extremely useful, both for the professor, teacher assistants, and the students themselves as a way to monitor the projects progress.

\section{EVALUATION}

Evaluation of the course is made accordingly to what the students proposed in their projects. Special attention is given to the proper functioning of the prototype; it is necessary to get the passing grade. Monthly seminars are given a weight of the $10 \%$, documentation a $20 \%$, and the functioning of the prototype $70 \%$.

Even though the course is not thought to promote competence between teams, the best projects are recognized on a public presentation where the students can show their prototypes to invited people from the media, as TV and news journals, industrial representatives, and family and friends. 


\section{PROJECT SAMPLES.}

As examples of proposed projects, we present the following student generated list:

1. Robot arm to classify objects by color using vision.

2. Automatic billiard player.

3 . Window cleaner for tall building.

4. Robot to automatically turn pianist scores.

5. Mobile robot for surveillance using map navigation.

6. Robotic arm to dispatch fuel.

7. Ostrich egg cleaner.

8. Control system for automatic parallel parking in a city.

9. Camera based tracking system for surveillance.

10. Automatic air hockey player.

11. Service robot for hotels or homes.

12. Robot for the automatic installation of optic fibers.

13. Robot to automatically prepare breakfast.

14. Mobile robot to collect tennis balls.

15. Automatic farm animal guidance.

16. Autonomous ship for the tracking of objects on the sea surface.

17. Object tracking with mobile robot.

18. Robot arm for assembling little pieces.

19. Intelligent camera security system.

20. Metallic objects transporter crane.

21. Mobile suitcase that follows the owner.

22. Mobile shopping cart that follows the owner.

23. Hexapode to watch for fires on woods.

24. Autonomous boat to detect and collect oil spills using computer vision.

After a common discussion session in which all the students and the professor participated, the following projects were chosen (corresponding to the spring 2004 course): $1,5,9,10,14,16,17$ and 20.

Figure 1 shows a mobile robot for surveillance using map navigation (project 5). The camera sent pictures of the surroundings to a desk computer using wireless technology. Figure 2 shows the prototype for the robot to pick up tennis balls (project 14). The balls are located using a frontal camera.

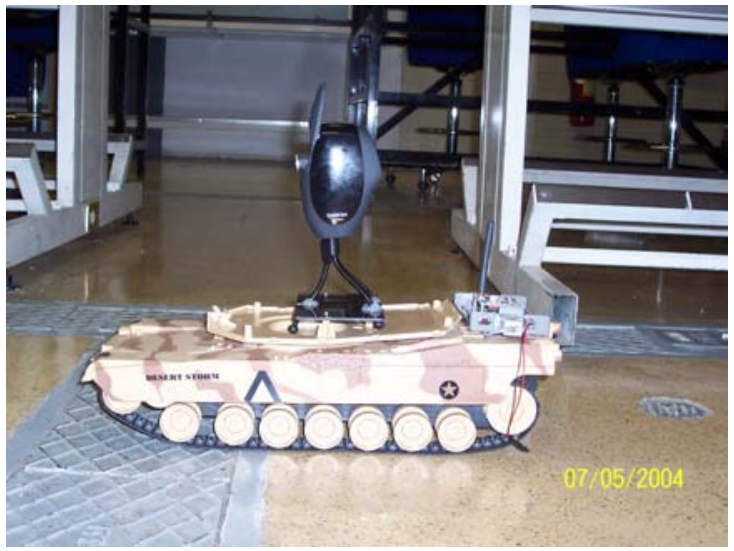

Figure 1. Mobile robot for surveillance.

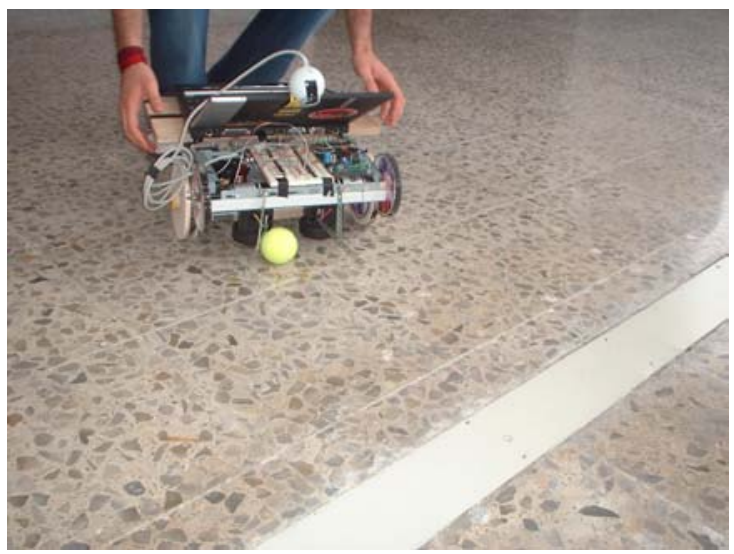

Figure 2. Robot to pick up tennis balls

Figure 3 shows a picture of project 20. The objects are located using images taken with a zenithal camera and picked up using a magnetic actuator.

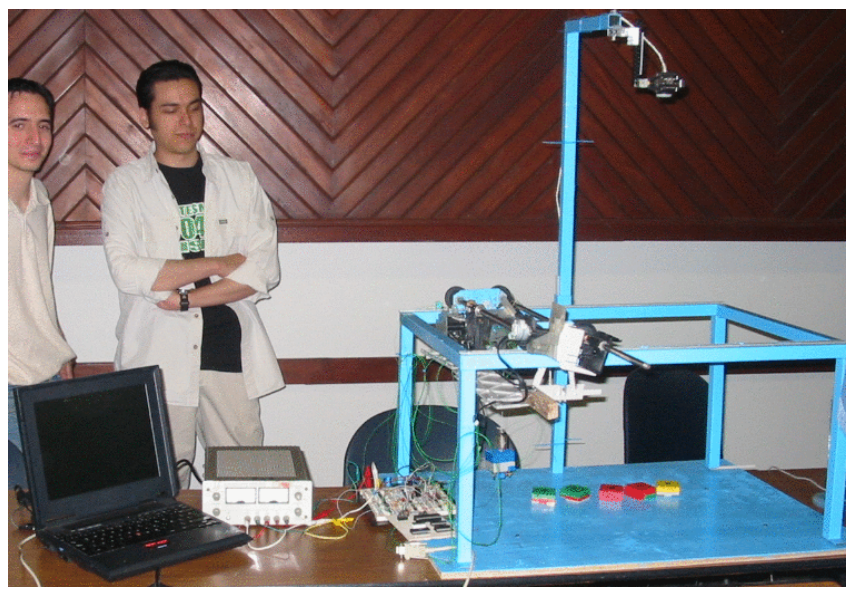

Figure 3. Metallic objects transporter crane. 


\section{CONCLUSIONS}

In this paper we describe the Robots Design course taught at the last semester at the undergraduate level of the Electronics System Engineering major of ITESM. The course is taught using project oriented and collaborative learning ideas, to encourage the students to work in teams to identify possible applications of robotics to everyday life problems. After 2 years of teaching the course using this schema, many original and creative prototypes have been developed by the students. As a result, the offering of this course has been extended to students on other related majors.

\section{REFERENCES}

[1] David W. Johnson and Roger T. Johnson, Learning together and alone: Cooperative, competitive and individualistic learning, Boston: Allyn and Bacon (1999).

[2] F. Kjersdam and S. Enemark, The Aalborg experiment: Project innovation in university education, Aalborg, Dinamarca: Aalborg University Press (1991).

[3] L. Greenwals and J. Kopena, On Achieving Educational and Research Goals with Small, Low-Cost Robot Platforms, IEEE Robotics and Automation Magazine, Vol. 9, No. 2, 25-32 (2003).

[4] B. Fagin, Ada/Mindstorms 3.0: A Computational Environment for Introductory Robotics and Programming, IEEE Robotics and Automation Magazine, Vol. 10, No. 2, 1924 (2003).

[5] F. Michaud, G. Lachiver, M. Lucas, and A. Clavet, ROBUS - A mobile robotic platform for Electrical and Computer Engineering Education, IEEE Robotics and Automation Magazine, Special Issue on "Robotics in Education: An Integrated Systems Approach to Teaching", 10(3):20-24. 